\title{
ON A NEW GENUS OF PORCELLANIDAE (CRUSTACEA-ANOMURA)*
}

\author{
By C. Sankarankutty \\ Central Marine Fisheries Research Institute, Mandapam Camp
}

The specimen described below was collected during one of the regular dredge operations near Manoli Island in the Gulf of Mannar at a depth of about 6 meters. Unfortunately this interesting form was not collected during the subsequent dredge operations, which may indicate its relative rarity.

\section{PSEUDOPORCELLANELLA n.gen.}

Description of the genus : Carapace longer than broad; front trilobed; cheliped short and stout; multiunguiculate dactylus of ambulatory leg; antenna reduced, its peduncle formed of three segments and flagellum consisting of few segments; Carpus in cheliped reduced.

Genotype: Pseudoporcellanella manoliensis, deposited in the type collection of the Central Marine Fisheries Research Institute, Mandapam Camp.

Description of the species: Pseudoporcellanella manoliensis n.sp.

The specimen representing the genus has an elongated carapace (Fig. 1), the breadth of which is about $2 / 5$ its length. The carapace is highly convex from side to side and its dorsal profile is straight. The dorsal surface of the carapace is traversed by transverse striae, which are more prominent towards the anterior end and the sides.

The front is trilobed, the median lobe of which is conical with a subacute tip and is much larger than the lateral lobes. The lateral lobes have their acute tips incurved. The borders of all the frontal lobes are unarmed. The outer orbital corner of the carapace has a triangular projection pointing antero-laterally, behind which the lateral borders of the carapace diverge upto about 3 the length of the carapace, converging again. The posterior border of the carapace is concave.

The basal antennular joint (Fig. 5) is suboval in shape and has a flat ventral side, the antennular flagellum being attached on the inner side. The antenna is removed from the orbit and is located in a sinus surrounded by three pointed triangular projections (Fig. 4); the outer orbital projection forming the dorsal, the pterygostomial projection forming the ventral and a similar spiny projection anterior to the antenna forming partly the lower border of the eye-peduncle. The antennal peduncle is formed of three segments, the second being the largest and the antennal flagellum is composed of only five segments. In the dorsal view of the animal, a few distal segments of the antenna alone are visible. Institute.

* Published with the kind permission of the Director, Central Marine Fisheries Research 
The ischium is the broadest segment of the external maxilliped (Fig. 2) and has a small lobe at the distal end of the outer side. The merus, when measured along the outer border, is the Jongest segment of the maxilliped.

The chelipeds are short, stout and subequal (Fig. $6 \& 7$ ). The merus when measured along the outer border is longer than the carpus. The carpus is a short segment and is slightly broader than long. The manus is flattened from side to side and is the largest segment in the cheliped, its length along the upper border is same as that of dactylus. The fingers are irregularly toothed along their cutting edges; the tips of the fingers are hooked and cross each other, the tip of the dactylus lying inside the tip of the fixed finger. The ventral border of the manus from the proximal end to the tip of the fixed finger has a fringe of bipinnate hairs, the latter increasing in numbers towards the tip. The dorsal border of the ditctylus also has a similar fringe of hairs and they are more concentrated at the tip.

The first three ambulatory legs (Fig. 3) are stout and of the same size. The merus is longer than the propodus, when measured along the outer border. The propodus has no spinule at the distal end of the ventral side. The dactylus is curved and carries three spinules, the middle one being the largest and the proximal one the smallest. The fourth leg is reduced as in the other porcellanids.

The abdomen consists of six segments, the second being the broadest. The telson is much longer than broad and has a central triangular plate on either side of which is a transverse division.

The ground colouration of the animal is milky white with transverse brownish bands on the carapace and the chelipeds. The carapace has two transverse bands near the anterior end, the first is larger than the second and runs between the orbits, and the second band immediately follows the first. The merus and the carpus of the cheliped have one transverse band each ; whereas the manus has two, the distal band widening towards the outer border of the segment. These bands are seen to disappear quickly on preservation.

\section{Measurements in millimeters :}

$\begin{array}{lll}\text { Length of carapace } & \ldots & 5.60 \\ \text { Breadth of carapace } & \ldots & 2.86 \\ \text { Length of manus of cheliped } & \ldots & 2.46 \\ \text { Breadth of manus of cheliped } & \ldots & 1.00 \\ \text { Length of dactylus of cheliped } & \ldots & 1.06 \\ \text { Breadth of carpus of cheliped } & \ldots & 1.00 \\ \text { Length of carpus of cheliped } & \ldots & 0.66 \\ \text { Length of merus of ambulatory leg } & \ldots & 1.00 \\ \text { Breadth of merus of ambulatory leg } & \ldots & 0.60\end{array}$

Holotype: A single immature specimen represents the holotype.

Locality : Gulf of Mannar at about 6 metres depth near Manoli Island.

Affinities: The characteristically reduced fourth ambulatory leg places this form in the tribe Galatheidea. The species, in having an abdomen closely pressed to the thorax and in the shape of the external maxilliped, shows its close affinity to the genera of the family Porcellanidae. The elongated carapace, trilobed front 


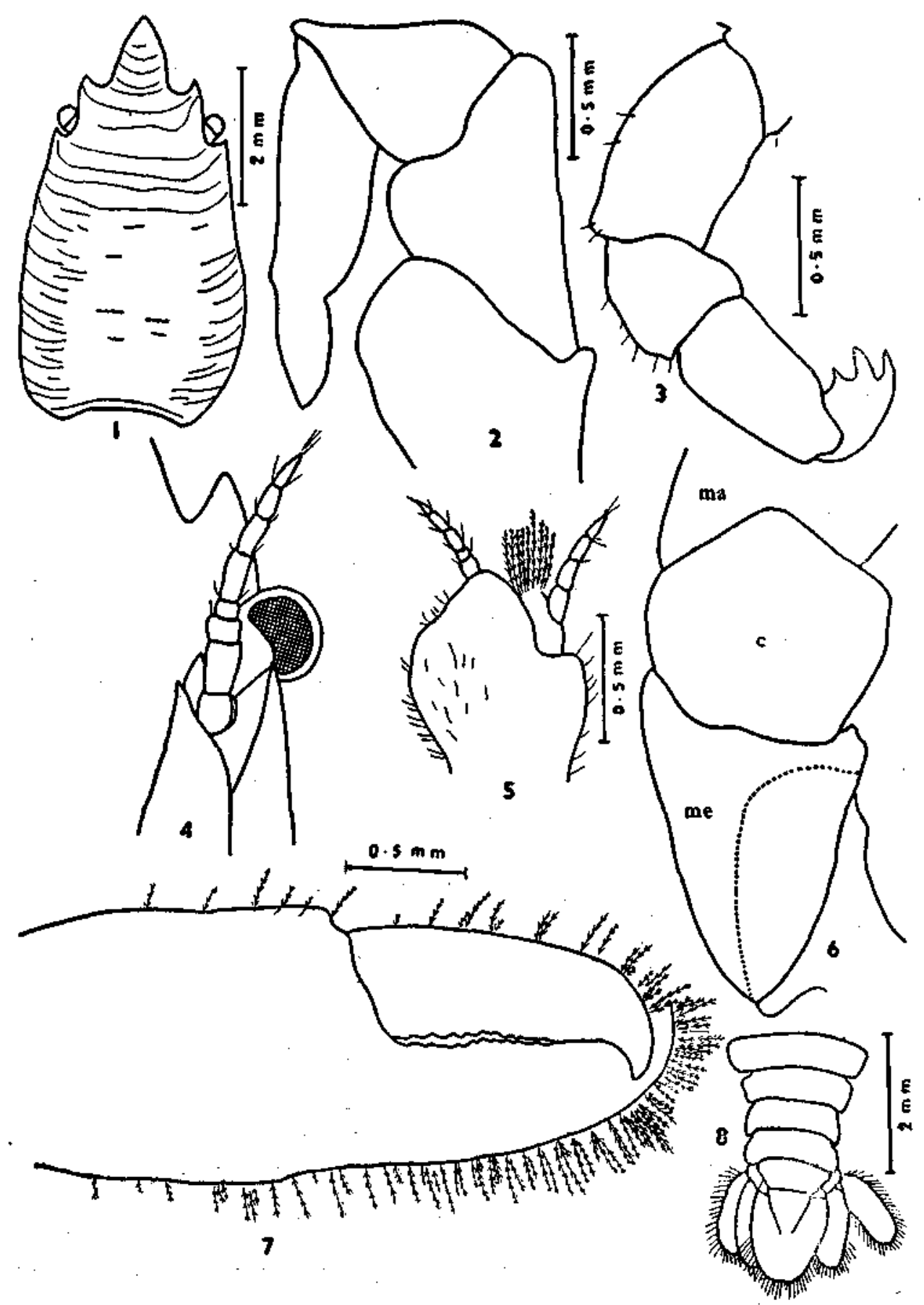

PSEUDOPORCELLANELLA

1. Dorsal surface of carapace; 2. External maxilliped; 3. Ambulatory leg; 4. Antenna in situ. 5. Basal antennular segment ; 6. Dorsal surface of cheliped showing ischium; merus (me), carpus (c), and proximal end of manus (ma); 7. Inner side of chela ; 8. Abdomen. 
and the triunguiculate dactylus of the ambulatory leg indicate its resemblance to the genus Porcellanella White.

However, because of the reduced antennal flagellum (the only other genus with reduced antennal fiagellum is Minyocerus Stimpson) and the reduced carpus of cheliped, the specimen comes closer to the true crabs. Hence it is proposed to designate this lone specimen as Pseudoporcellanella manoliensis. Gen. et. sp. nov. When sufficient material of this interesting form becomes available, perhaps it will be possible to elucidate its exact systematic position.

\section{SUMMARY}

A new genus Pseudoporcellanella (Family-Porcellanidae) has been created to accommodate a new species $P$. manoliensis. The description of the new genus and species has been given and its affinities have been discussed.

\section{ACKNOWLEDGEMENTS}

I wish to express my grateful thanks to Dr. Jones, Director, Central Marine Fisheries Research Institute, for his guidance and encouragements during my work. I am also indebted to Dr. Janet Haig of the Allan Hancock Foundation for confirming my identification and for her valuable suggestions. I also wish to express my thanks to Dr, R. Raghu Prasad for kindly going through the manuscript and offering valuable suggestions. My thanks are also due to Dr. R. P. Varma, Dr. E. G. Silas and Shri P. R. S. Tampi for constructive criticisms.

\section{REFERE NCES}

Barnard, K. H. 1950. Descriptive catalogue of South African Decapod Crustacea (Crabs and Shrimps). Ann. S.Afr. Mus. $38: 1-824$.

Gravely, F. H. 1927. Order Decapod (except Paguridea) and Stomatopoda in : The littoral Fauna of Krusadai Island in the Gulf of Mannar. Bull. Madras Govt. Mus. (n.s.) 1 (1): 135. 141.

HaIG, Janer. 1955. Reports of the Lund University Chilie expedition, 1948-49, 20. The Crustacea Anomura of Chilie. Lund. Univ. Arsskr., N.F., Avd., Bd. 51, Nr. 12: 1-68.

- 1956. The Galatheidea (Crustacea Anomura) of the Allan Hancock Atlantic Expedition with a review of the Porcellanidae of the Western North Atlantic; Los Angeles, Allan Hancock Atlantic Expedition, No. $8: 1-44$.

1957. The Porcellanid crabs of the "Askoy" Expedition to the Panama Bight. Published by the American Museum of Natural History, New York 24, Number 1865 : 1-17.

Hendorson, J. R. 1893. A contribution to the Indian Carcinology. Trans. Linn. Soc. London (Zool.) $5(2): 325-458$.

Southwel, T. 1909, Report on the Anomura collected by Mr. James Hornell at Okhamandal in Kathiawar in 1905-06. Marine Zoology of Okhamandal by Hornell. Williams and Norgate, London 1909, Part I : 105-123. 